\title{
Computers in Libraries 2000
}

\author{
Highlights from the 15th annual conference
}

\author{
by Peter V. Deekle
}

$\mathrm{C}$ omputers in Libraries 2000, prepared in cooperation with the Special Libraries Association, was held in Washington, D.C., March 15-17. Its sponsor, Information Today, Inc., described it as "North America's largest technology conference and exhibition for librarians and information managers," and, if initial estimates reflected actual attendance, more than 3,000 persons attended the threeday event.

For those unfamiliar with the conference format, each day consists of concurrent morning and afternoon tracks, with pre- and postconference daylong programs before and after the main conference. All conferees receive published proceedings at the onsite registration desk.

Among the sessions I attended for the Learning: Training and Instruction track, was "Virtual Instruction-Tutorials and Literacy." The two presenters, Erica Lilly from Kent State and Karen Hartman from Mary Washington College, highlighted unique Web tutorials and the means for their creation and maintenance. Crediting ACRL's "Guidelines for Distance Learning Library Services" as a basis for planning and setting service priorities, they demonstrated models of virtual reference service.

\section{How to do it on the Web}

I particularly appreciate the variety of program types at this conference, ranging from panel discussions and presentations to demonstration sessions and practical "how to" sessions. The latter included "How to Do It on the Web" featuring the Bibliographical Center for Research's Michael Sauer and Laura Cohen from the University of Albany. They conducted a session on how to teach searching skills for a dynamic Web environment. For another program Karen Hartman joined Tufts University's Regina Raboin for "Networked Teaching-What to Teach and How." They offered interesting approaches to teaching the "essential Web" in 50 minutes.

\section{Digitizing, ownership, and future}

A whole track at the conference was devoted to the design and maintenance of library Web sites. Annemarie Del Vecchio of LEXIS-NEXIS moderated three successive sessions. Design tips, promotional strategies, and advice on overcoming hurdles were reported by presenters from academic libraries.

Content and collections were the substance of "Digitizing Case Studies." These two consecutive sessions on the second day included a live demonstration by Carol Ann Hughes, of the University of Iowa, of a digitized special collection project. The second program highlighted the use of digital media technology in producing machine-readable documents for all major United Nations organs by Nathalie Leroy and the Army Research

\section{About the author}

PeterV.Deekle is college librarianatWheaton College, e-mail:pdeekle@wheatoncollege.edu 
Laboratory's digital collection (over 5,000 PDF files) of technical reports by Lillian Woon Gassie.

Not all of the programs concerned services and resources. W. Lee Hisle of Connecticut College and Danielle Mihram from the University of Southern California joined a panel of attorneys, legal policy analysts, and the Register of Copyrights in a wide-ranging presentation concerning ownership rights, censorship, and protection. This session raised ethical and legal questions for libraries and society regarding an individual's right to unrestricted information access, regardless of an individual's age.

Forecasting trends and developments has always been a significant part of this conference. Laverna Saunders of Salem State College, provided a comprehensive description of the virtual academic library and its impact on staff, organization, work styles, and outcomes measures. But in his presentation, "Yes, They Still Want to Print!" David Bennett of Robert Morris College, reminded conferees that as electronic resources increase in number and variety, more patrons want to print copies.

Computers in Libraries has established a tradition for evening hospitality venues. This year, the evening "Technology and Knowledge Forum: A Look at Dead and Emerging Technologies," an informal panel of presenters, opened this social/post prandial event with a rousing rendition of The Beatles's "Hard Days Night." During a free-wheeling exchange of opinions, panelists traded concerns and predictions, including: worries about the Microsoft stranglehold on creative development, the proliferation of new search engines designed by persons without indexing or metadata knowledge, limitations of bandwidth for information access, and a worrisome shortage of librarians in this "information age."

One reason the conference moved from its Crystal City, Virginia, site was the need for more exhibit space, which the present venue at the Washington Hilton provides. Nearly 100 information technology vendors participated. Their generous sponsorship provided the means for the diverse program offerings throughout the conference week.

Computers in Libraries 2000 proved, once more, that a conference with "something for everyone" could be both educational and entertaining.

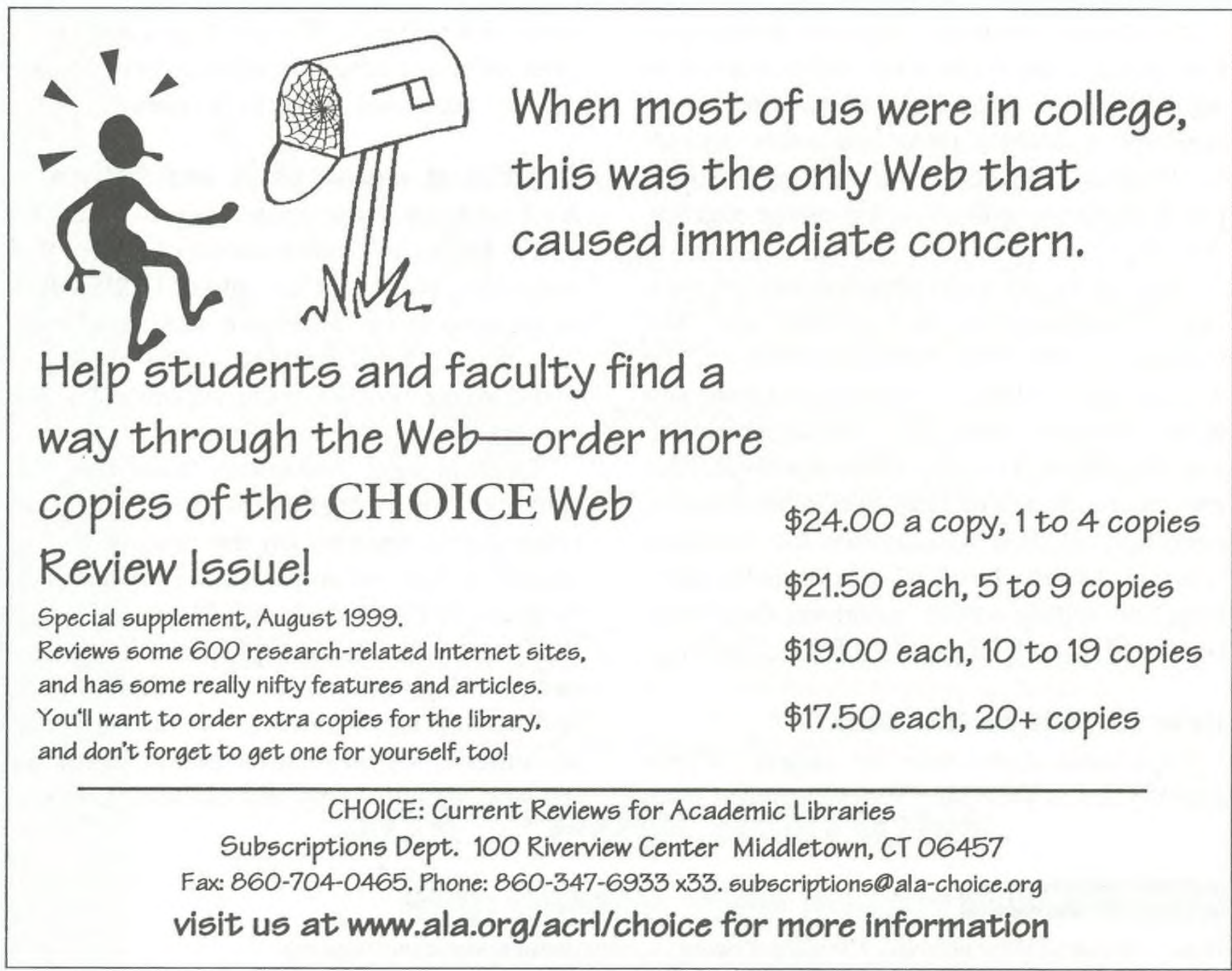


"The ARL Japan Journal Access Project has broken down international barriers to create a resource sharing model that can be applied worldwide. OCLC contributed to the success of this initiative with their ILL and ILL Fee Management services."

\author{
Mary E. Jackson
}

Senior Program Officer for Access Services, Association of Research Libraries

The Japan Journal Access Project is a collaborative effort involving Waseda University (one of Japan's leading research institutions), 18 research libraries in Canada and the U.S., the Association of Research Libraries and OCLC. This project gives students and scholars easy access to Waseda University's extensive collection of materials via the OCLC global resourcesharing network.

Most notably, the ILL Fee Management service eliminates difficulties associated with currency exchange by providing a single invoice in local funds.

For over 25 years, libraries have been working together through OCLC to further access to information and reduce library costs. OCLC member libraries cooperatively created WorldCat ${ }^{\oplus}$ (the OCLC Online Union Catalog), which is now the most consulted database in higher education.

At OCLC we continue to develop new ways to provide innovative and affordable library services for our membership. For example, we are working with 200 OCLC member libraries on an international research initiative that is using automated cataloging tools and library cooperation to create a research-quality database of Web resources.

For information about what you can do now with OCLC services, please contact us at:

purl.oclc.org/oclc/crin 1-800-848-5878, ext. 6251 


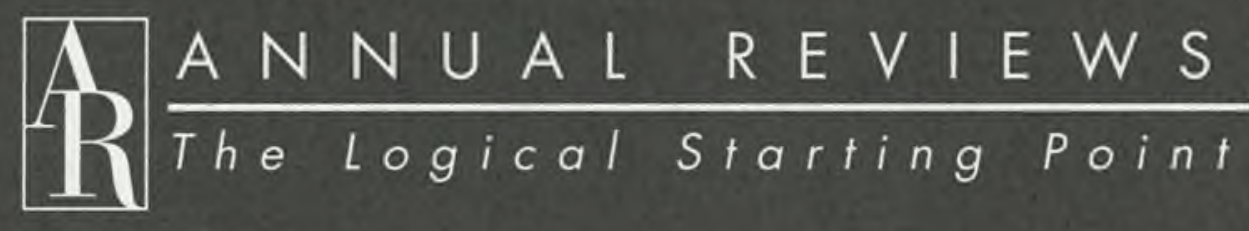 \\ Creating \\ Site License \\ Solutions}

The Most Highly Cited

Collection of Review Literature in the Biomedical, Physical, and Social Sciences.

\section{Essential New Titles}

Annual Review of Biomedical Engineering

Volume 1, August 1999

Annual Review of Genomics and

Human Genetics

Volume 1 , July 2000

Annual Review of Political Science

Volume 2, June 1999

For a Custom Site License Agreement or Consortium Pricing, Contact:

Andrea Lopez

Site License Account Manager

800.523 .8635 ext. 647 in USA/CAN

650.843.6647 Worldwide

650.424.0910 Fax

alopez@annualreviews.org

Special Discounts Apply When You Increase Your Current Number of Subscriptions.

Call Toll-free 800.523.8635 ext. 1 in

USA/CAN

or 650.493.4400 ext. Worldwide to order.

Fax orders to 650.424 .0910

Order Online at www.AnnualReviews.org

email: service@annurev.org

Annual Reviews

4139 El Camino Way

P.O. Box 10139

Palo Alto, CA 94303-0139 USA

PRIORITY ORDER CODE: CRLN2000

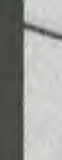

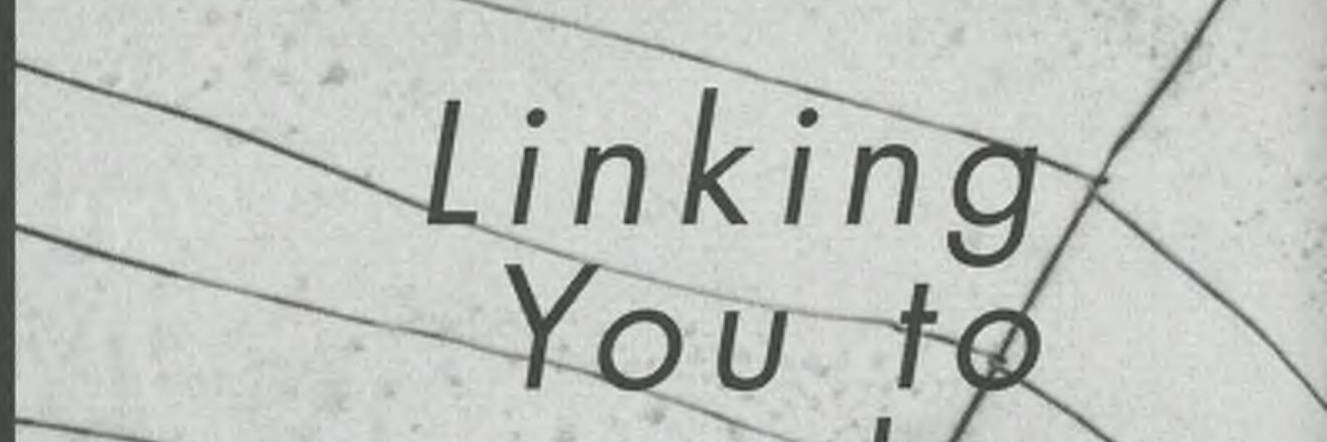

World of Releyant Resoarch (x) high quality publications offered at reasonable prices."

Garrett Eastman

Librarian

Rowland Institute for

Science,

Cambridge, MA

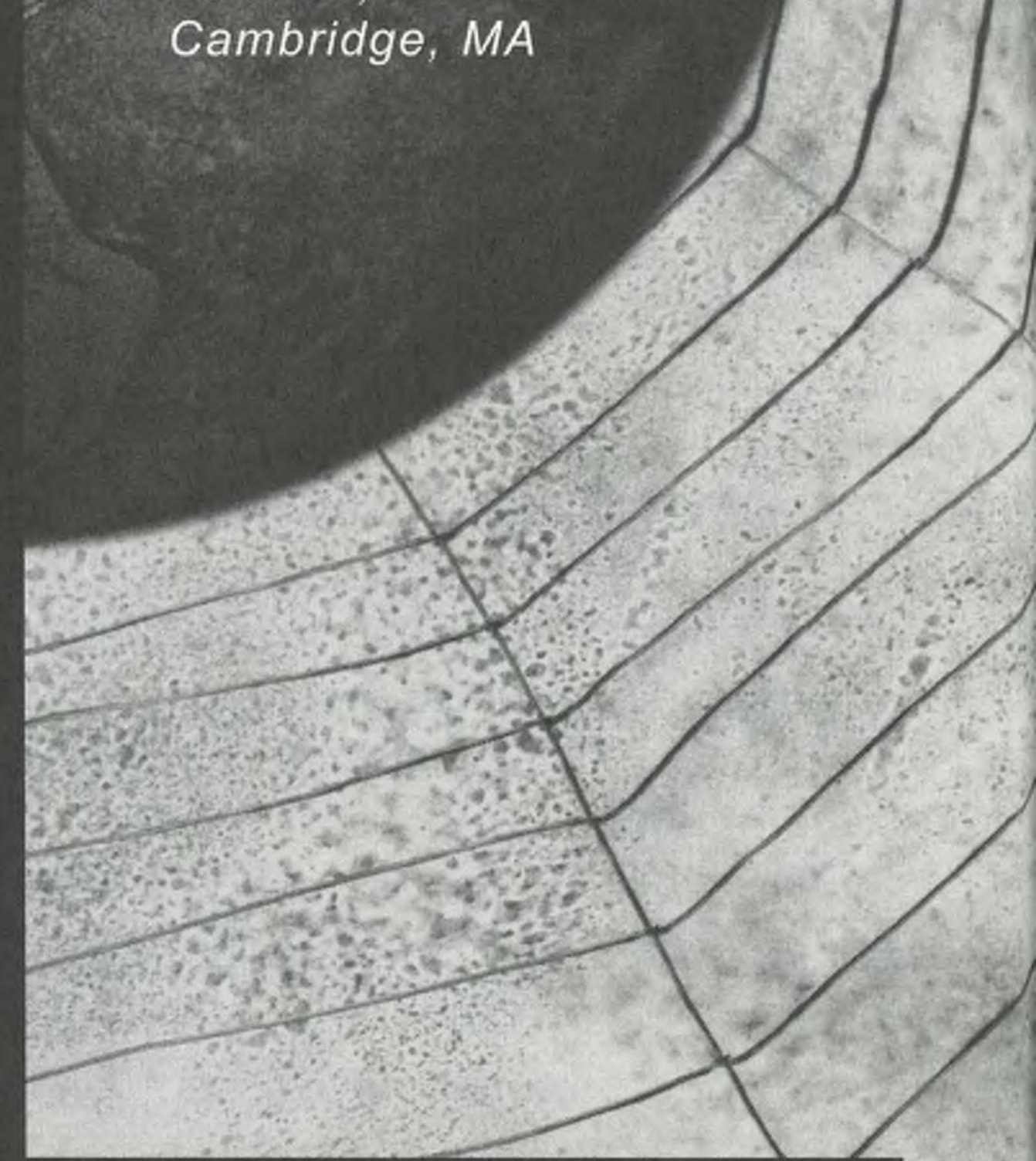

